\title{
Drone Delivery Models for Healthcare
}

\author{
Judy E. Scott \\ University of Colorado Denver, USA \\ judy.scott@ucdenver.edu
}

\author{
Carlton H. Scott \\ University of California Irvine, USA \\ chscott@uci.edu
}

\begin{abstract}
Just as the mobile phone allowed developing countries to leapfrog technology in personal communication, the delivery drone has the potential to have the same effect on traditional transportation infrastructure. Inaccessible roads no longer will prevent delivery of blood, medications or other healthcare items. This paper reviews the current status of innovative drone delivery with a particular emphasis on healthcare. The leading companies in this field and their different strategies are studied. Further we review the latest decision models that facilitate management decision making for operating a drone fleet. Our contribution in this paper of two new models associated with the design of a drone healthcare delivery network will facilitate more timely, efficient and economical drone healthcare delivery to potentially save lives.
\end{abstract}

\section{Introduction}

There is a major new technology that is destined to be a disruptive force in the field of transportation: the drone. Just as the mobile phone allowed developing countries to leapfrog older technologies for personal communication, the drone has the potential to leapfrog traditional transportation infrastructure.

Drones are commonly known as unmanned aerial vehicles (UAVs) [2]. Alternative terms include Unmanned Aircraft (UA), Remotely Operated Aircraft (ROA), Remotely Piloted Vehicle (RPV) and Remotely Piloted Aircraft (RPA) [3].

Recent innovations have taken place in drone specific hardware, software and networks. For example, light composite materials and global positioning systems (GPS) enable efficient flight. Furthermore, lithium batteries are rapidly improving so drones can fly further on a charge [18]. Drone software can use mobile phone or tablet apps for tracking and navigation [9, 12, 19]. The drone operating system manages the network by monitoring weather data from all the ground stations and optimizing the routes of the drones [19]. The routes need to avoid adverse weather conditions and avoid other risk factors. Also, an on board webcam can enable communication with a control center [17].

Although the definition of drones is complex because of the diversity of characteristics [22, 3], it is generally agreed that drones are devices which are capable of sustained flight, which do not have a human on board, and are under sufficient control to perform useful functions.

Useful drone functions include delivery of small items that are urgently needed in locations with difficult access. Timely delivery of urgently needed medications, blood and vaccines are critical in healthcare. However, locations needing the delivery may have difficult access due to poor transportation infrastructure, or roads blocked by severe weather, disasters or traffic congestion. Since a drone can fly over an inaccessible road, innovative organizations have begun to use drones for healthcare delivery. In section three, we provide a review of known examples.

To our knowledge, this study is one of the first academic papers published on drone delivery models for healthcare. While the limited academic literature published on modeling drone delivery has focused on parcel delivery, this paper provides two new models for drone delivery in a healthcare context. A logistics network is designed to provide timely delivery of healthcare items using a tandem strategy involving land-based transportation and final delivery by drone. Both models focus on locating a warehouse with supplies and drone nests to complete final delivery. In the first model our objective is to minimize the total weighted time for delivery; the second model seeks to minimize the maximum weighted time to any delivery point thereby ensuring more equitable service to outlying regions. For a review of location decisions see [5].

The next section of the paper overviews drone applications and drone issues that need to be addressed. The third section describes drone applications in healthcare. In section 4, we review 
previous modelling work in drone package delivery before developing new models with healthcare applications in mind. The final section has concluding remarks. An appendix provides data used in numerical examples.

\section{Background on drone applications}

Many drone applications involve surveillance using an on board camera. However, drones also are capable of carrying devices other than cameras and capable of delivering small loads. Drones have been used extensively by the military in combat and for humanitarian aid. Useful non-military drone applications in different industries include agriculture surveillance and crop spraying, shark surveillance at beaches, monitoring wildlife for conservation, monitoring fires, scientific research and exploration, monitoring riots and international borders by police and governments, sports and entertainment event coverage, other media coverage, emergency services and disaster response [2, 3, 6].

Arguably, humanitarian drone applications are the most useful since human lives are at stake. For example, in Nepal after the 2015 earthquake, drones helped rescuers locate survivors [2].

In contrast to humanitarian drone applications, drones have been used for crimes, such as delivering contraband to prison inmates, firing weapons, terrorism and hacking [2].

Also drones have been criticized for inadequate regulation, safety issues and security and privacy abuse [3, 24]. Celebrities and others are concerned that drones will spy on them. Furthermore, irresponsible drone owners have been a nuisance in cases related to photographing accidents or fires and interfering with emergency responders [2]. Other concerns are that people would shoot down drones and steal drone packages [24].

Regulatory bodies, such as the Federal Aviation Administration (FAA), usually ban commercial drones because they are wary of collisions in airline air space. Nevertheless, there have been reports of hundreds of collision close calls many due to noncommercial drones [6].

Since December 2015, drones weighing between .55 and 55 pounds need to be registered with the FAA and marked with the registration number so owners can be identified if there is an accident or criminal use of the drone [2]. Owners need to follow FAA restrictions, which currently only allow drone flights during daylight hours, within line of sight, not over people etc.
In the US, commercial drone use is illegal without a Section 333 exemption [9]. FAA exemptions have been granted for surveillance applications, for example BP pipelines, rather than delivery. This has been frustrating to Amazon and other companies that are planning drone delivery [24]. As discussed in the next section, Flirtey has had FAA approval for dropping medical supplies in rural Virginia with drones $[10,14]$. However, the approval was only for a weekend. In contrast, countries with urgent healthcare needs, such as Rwanda, are more likely to quickly overcome regulatory hurdles [9].

\section{Drone applications in healthcare}

Drone applications in healthcare include delivery of medicine, defibrillators, blood samples, and vaccines [1, 2, 4, 10, 12, 14, 16, 17, 19, 20, 21].

For example, autonomous drones, such as those employed by Matternet, use GPS and other sensors to navigate between automated ground stations in order to deliver medications in remote locations that lack adequate roads [19]. Matternet has delivered medications in Haiti following the 2010 earthquake and in the Dominican Republic [2], as well as in New Guinea and Switzerland [9]. The company works with UNICEF and Doctors without Borders.

Matternet's drones can carry one to two kilograms (2.2 to 4.4 pounds) and transport items about $10 \mathrm{~km}$, traveling up to $40 \mathrm{~km}$ per hour, taking about 18 minutes including lift off and landing [9, 18, 19]. A smartphone app enables senders to choose from a list of possible destinations. The drone then automatically generates a route based on the terrain, weather, and airspace and population density. The route will avoid airports, schools and public squares, as well as hills and buildings. A parachute will deploy in an emergency.

Table 1. Comparison of drone healthcare delivery

\begin{tabular}{|l|l|l|}
\hline $\begin{array}{l}\text { Drone } \\
\text { company }\end{array}$ & Healthcare items & Delivery location \\
\hline Matternet & Blood, medications & $\begin{array}{l}\text { Haiti, Dominican } \\
\text { Republic, Papua } \\
\text { New Guinea, } \\
\text { Switzerland }\end{array}$ \\
\hline DHL Parcel & Blood, medications & Germany \\
\hline Zipline & Vaccines, blood & Rwanda \\
\hline Flirtey & Medications & Virginia, Nevada \\
\hline $\begin{array}{l}\text { Delft } \\
\text { University }\end{array}$ & Defibrillators & Netherlands \\
\hline
\end{tabular}

In Germany, DHL Parcel has researched three generations of medical drone delivery called 
Parcelcopter [4]. The first generation travelled $1 \mathrm{~km}$ to deliver blood samples across the Rhine River at Bonn. The second generation tested drone delivery of medications and other urgently needed material for three months in 2014 to Juist, one of Germany's remote North Sea Islands [1, 21]. The Parcelcopter traveled $12 \mathrm{~km}$ across open sea. From January to March 2016, DHL's third generation Parcelcopter tested delivery of over 130 parcels of urgently needed medicines or sporting goods between automated Skyports in two Bavarian Alpine villages. Drone delivery took 8 minutes compared to a 30 minute road trip in winter [4]. The time difference could be significant in a medical emergency.

UPS and Zipline are working on a drone network to deliver vaccines and blood to 20 clinics in remote locations in Rwanda [20, 12, 16]. Malaria, infant deaths and mothers dying in childbirth are common in Rwanda. When rabies vaccine is needed urgently, drone delivery would not be hindered by washed out roads during rainy season. Only a third of Africans live within two kilometers of a road that functions year-round [12]. Zipline drones are launched from a nest and make a delivery by dropping items with a paper parachute. After the drone returns to the nest a sim card and new battery are inserted along with the blood or vaccines for the next delivery.

Zipline drones are the size of a large dog and can carry three pounds [12]. They can fly 45 miles in 30 minutes. Their route is tracked and changed with a tablet app.

Table 2. Comparison of healthcare delivery drones

\begin{tabular}{|l|l|l|}
\hline $\begin{array}{l}\text { Drone } \\
\text { company }\end{array}$ & Launching pad & Delivery method \\
\hline Matternet & $\begin{array}{l}\text { Automated } \\
\text { ground station }\end{array}$ & $\begin{array}{l}\text { Automated } \\
\text { ground station }\end{array}$ \\
\hline DHL Parcel & $\begin{array}{l}\text { Automated } \\
\text { Skyport }\end{array}$ & $\begin{array}{l}\text { Automated } \\
\text { Skyport }\end{array}$ \\
\hline Zipline & Nest & Paper parachute \\
\hline Flirtey & Airport & Dropped by rope \\
\hline $\begin{array}{l}\text { Delft } \\
\text { University }\end{array}$ & Hospital, clinic? & Ground landing \\
\hline
\end{tabular}

The first FAA-approved drone delivery successfully dropped medical supplies to a health clinic in rural southwest Virginia [14]. The clinic operates for about 3000 patients one weekend each year [10]. Flirtey drones delivered prescription items from the Wise County Regional airport to the clinic in the remote fairgrounds in about 3 minutes. Delivery is usually 90 minutes along a winding bumpy road from the pharmacy in Oakwood 35 miles away. An experimental National Aeronautics and Space Administration (NASA) manned drone delivered from Oakwood to the Wise County airport since Flirtey drone batteries at that time were limited to about 20 miles. Flirtey drones have also delivered healthcare items in Nevada, Australia and New Zealand.

Table 3. Comparison of healthcare delivery drone payload, range and speed

\begin{tabular}{|l|l|l|l|}
\hline $\begin{array}{l}\text { Drone } \\
\text { company }\end{array}$ & Payload & Range & Speed \\
\hline Matternet & $\begin{array}{l}2 \mathrm{~kg} \\
(4.4 \mathrm{lb})\end{array}$ & $\begin{array}{l}10 \mathrm{~km} \\
(6.25 \mathrm{miles})\end{array}$ & $\begin{array}{l}40 \mathrm{kmph} \\
25 \mathrm{mph}\end{array}$ \\
\hline $\begin{array}{l}\text { DHL } \\
\text { Parcel }\end{array}$ & $4.4 \mathrm{lb}$ & $\begin{array}{l}12 \mathrm{~km} \\
(7.5 \mathrm{miles})\end{array}$ & $>40 \mathrm{mph}$ \\
\hline Zipline & $3 \mathrm{lb}$ & 45 miles & $90 \mathrm{mph}$ \\
\hline Flirtey & $\begin{array}{l}2 \mathrm{~kg} \\
(4.4 \mathrm{lb})\end{array}$ & $20 \mathrm{miles}$ & $?$ \\
\hline $\begin{array}{l}\text { Delft } \\
\text { University }\end{array}$ & $\begin{array}{l}4 \mathrm{~kg} \\
(8.8 \mathrm{lb})\end{array}$ & $\begin{array}{l}12 \mathrm{~km} \\
(7.5 \mathrm{miles})\end{array}$ & $60 \mathrm{mph}$ \\
\hline
\end{tabular}

In the Netherlands, prototype ambulance drones have demonstrated delivery of defibrillators [17]. Traveling at speeds of up to 60 miles per hour, the drones can reach patients within a 4.6 square mile radius in a minute versus an average of 10 minutes for traditional emergency services. The faster drone response increases the chance of survival to $80 \%$ versus $8 \%$ for traditional emergency services. The drones track emergency mobile calls and use GPS to navigate. A paramedic, from a control room connected to a livestream web camera on the drone, can instruct a lay person assisting the patient. It is expected to take five years to develop an operational emergency drone network and address legal issues and improve the steering on the drones which will cost $\$ 19,000$ each. There is potential for "flying medical toolbox" drones to carry other healthcare devices, such as oxygen masks or insulin injections for diabetes patients.

Table 1 shows that the healthcare items transported by the drones are predominantly medications, blood and vaccines. Potentially, defibrillators, oxygen and insulin could be transported by the ambulance drone, which is only a prototype currently.

In Table 2, we see that the launching pad is often automated and called a ground station, Skyport or nest. The delivery method can be the same, as in the case of Matternet and DHL Parcel or the load can be dropped as in the case of Zipline, by a paper parachute, and Flirtey dropped by rope.

Table 3 compares the payload, range and speed for the different drone delivery platforms. Matternet, DHL and Flirtey all carry about the same payload. Zipline carries a smaller payload but is much faster 
than the others because of its streamlined fixed wing plane design versus the helicopter-like design of the others. The range varies from Matternet's 6.5 miles to Zipline's 45 miles. Note that these numbers are based on reported information in articles and websites and may not reflect current capabilities. Also, as stated earlier, technology, such as the duration of the charge of lithium batteries, is rapidly improving.

In the next section, we develop a particular type of model for location decisions that has application for the drone delivery of healthcare related items.

\section{Model Development}

Several researchers have looked at various models for drone use primarily for parcel delivery inspired by Google, Amazon and DHL who are exploring this option. Murray and Chu develop two models for delivery of parcels by drones [13]. They envisage that the primary delivery vehicle would be a truck but with attendant drones to be launched from a truck. They model this as a mixed integer program of a travelling salesman type. Computational issues associated with this model have been discussed by [23]. Related models have been given by Ponza [15], Agatz et. al. [1] and Ferrandez et. al. [7] who use various meta-heuristic approaches to solve the resulting integer programs. These papers essentially conclude that there are cost savings to be realized when both trucks and drone work jointly to deliver parcels. Hong et.al. [11] develop a sole drone based delivery system for urban areas by positioning drone recharging stations and routing delivery paths around obstacles.

We consider a scenario where emergency medical supplies need to be delivered to an outlying area that is not completely served by good roads but is too far for drone delivery alone. This is often the case in an undeveloped country. Consequently a tandem strategy is adopted whereby land-based transportation is used to deliver from a warehouse (which could be a storage area at a hospital or clinic) where supplies are stored to a drone nest which is in sufficient proximity to the area of need. The problem at hand is to position both the warehouse that is served by road and the drone nests that are needed to serve the "last mile" delivery to the area of need.

We partition the area to be served into a number of demand clusters which could represent a village or group of villages, for example, and attempt to assign a drone nest to each demand cluster. A demand cluster would then consist of a number of demand points for emergency supplies.

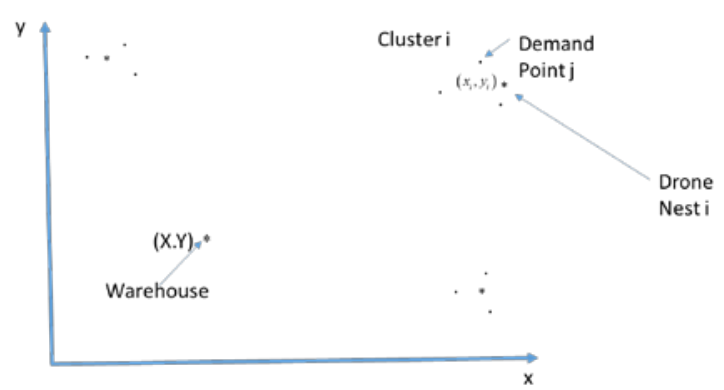

Figure 1. Location of warehouse, drone nests and demand points

We provide two models to address the above location decisions. Our first model has as objective to minimize the total weighted delivery time; road plus air. A downside of this objective is that some demand clusters or demand points within a cluster may have unacceptably long delivery times. An alternative type of model is to minimize the maximum weighted time to deliver to all demand points in all demand clusters. Generally this approach would lead to more equitable delivery times. Since there is a tradeoff between delivery time and cost, all models contain a budget constraint.

\subsection{Model 1}

\section{For Model 1:}

Minimize total weighted time for truck/drone delivery subject to a budget and drone travel constraint.

$$
\begin{aligned}
& v_{t}, v_{d} \text { are velocity of truck, drone } v_{t}<v_{d} \\
& c_{t}, C_{d} \text { are per unit costs of operation per mile for }
\end{aligned}
$$
a truck and drone respectively.

Deliveries take place from a central depot at $(X$, $Y$ ) by truck to a point $\left(x_{i}, y_{i}\right), i=1, \ldots, n$ which are drone nests associated with a demand cluster. Final delivery is by drone to a demand point $\left(a_{i j}, b_{i j}\right), j=1, \ldots, m_{i}$. Here $m_{i}$ is the number of demand points served by drone nest $i$.

$$
d_{i}(\cdot, \cdot), d_{i j}(\cdot, \cdot) \text { are distance functions and }
$$
$w_{i}, w_{i j}$ are weights with $w_{i}=\sum_{j} w_{i j}$. These are essentially the demand at each point $\left(a_{i j}, b_{i j}\right)$, and conservation of demand flow at drone nest $\left(x_{i}, y_{i}\right) . B$ is budget, $D$ is limit on drone travel. We have the following mathematical program.

Minimize Total Weighted Time over $X$ and $X_{i}$ 
$\sum_{i} \frac{w_{i} d_{i}\left(X-x_{i}, Y-y_{i}\right)}{v_{t}}+\sum_{i} \sum_{j} \frac{w_{i j} d_{i j}\left(x_{i}-a_{i j}, y_{i}-b_{i j}\right)}{v_{d}}$

subject to

$$
\begin{aligned}
& \sum_{i} c_{t} w_{i} d_{i}\left(X-x_{i}, Y-y_{i}\right)+\sum_{i} \sum_{j} c_{d} w_{i j} d_{i j}\left(x_{i}-a_{i j}, y_{i}-b_{i j}\right) \leq B \\
& d_{i j}\left(x_{i}-a_{i j}, y_{i}-b_{i j}\right) \leq D \forall(i, j) \\
& \text { Define } z_{i 1}=X-x_{i}, z_{i 2}=Y-y_{i} \quad \text {.The above }
\end{aligned}
$$

program is then seen to be convex since $d_{i}$ and $d_{i j}$ are convex functions.

\subsection{Model 2}

\section{For Model 2:}

Minimize Maximum weighted time for truck/drone delivery subject to a budget and drone travel distance constraint.

The objective may be written as

$$
\underset{X, x}{\operatorname{Min}} \operatorname{Max}_{i, j}\left[\frac{w_{i} d_{i}\left(X-x_{i}, Y-y_{i}\right)}{v_{t}}+\frac{w_{i j} d_{i}\left(x_{i j}-a_{i j}, y_{i j}-b_{i j}\right)}{v_{d}}\right]
$$

resulting in the following convex program (where we introduce a new variable $T$ )

$\operatorname{Min} T$

subject to

$$
\begin{aligned}
& \frac{w_{i} d_{i}\left(X-x_{i}, Y-y_{i}\right)}{v_{t}}+\frac{w_{i j} d_{i}\left(x_{i j}-a_{i j}, y_{i}-b_{i j}\right)}{v_{d}} \leq T \quad \forall i, j \\
& \sum_{i} c_{t} w_{i} d_{i}\left(X-x_{i}, Y-y_{i}\right)+\sum_{i} \sum_{j} c_{d} w_{i j} d_{i j}\left(x_{i}-a_{i j}, y_{i}-b_{i j}\right) \leq B \\
& d_{i j}\left(x_{i}-a_{i j}, y_{i}-b_{i j}\right) \leq D \forall(i, j)
\end{aligned}
$$

Here $T$ is the maximum weighted time for delivery to any demand point. In the next section, we look at the use of these two models to both position assets (storage facilities and drone nests) and to assist managerial decision making with respect to budget allocation.

\subsection{Numerical Results.}

We look at a simple example involving three demand clusters each serving three demand points. Drones can travel at 50 miles per hour and trucks at 40 mile per hour. Costs are very difficult to pinpoint. Welch looks at costs for Amazon Prime Air [24] but it is doubtful that these estimates would apply in an undeveloped country. Matternet estimates that drones would cost twenty four cents for a six mile 15 minute trip by drone [2]. Since drones generally carry one item at a time and trucks many items we assume that the unit cost per mile to deliver by drone is twice that for a truck in our base model. Further we assume that drones are limited to 100 miles per delivery trip so the delivery point needs to be no more than 50 miles from the nest. This is actually more than current capability of a drone but we anticipate that battery life will significantly improve and extend trip times. In any case, the models are general and better estimates can be used as they become available. The overall budget will be chosen to enable feasible delivery times. Weights (demand estimates) are also used in the models. Detailed values are given in the Appendix.

Drones are assumed to fly in straight lines (no obstacles) so a Euclidean metric is appropriate; trucks on the other hand need to follow the road network. In this initial paper, we assume that the distance metric for trucks is a modified Euclidean metric that is empirically derived. In this case, we model the distance as 1.6 times the Euclidean metric. This is somewhat higher than empirical values used in the US (say $\approx 1.3$ ) but reflects the fact that an undeveloped nation's road network is somewhat inferior.

Hence

$$
d_{i}\left(X-x_{i}, Y-y_{i}\right)=1.6\left(\left(X-x_{i}\right)^{2}+\left(Y-y_{i}\right)^{2}\right)^{.5} \forall i
$$

and

$$
d_{i j}\left(x_{i}-a_{i j}, y_{i}-b_{i j}\right)=\left(\left(x_{i}-a_{i j}\right)^{2}+\left(y_{i}-b_{i j}\right)^{2}\right)^{.5} \forall i, j .
$$

The models are now solved using AMPL/MINOS [8]. Since all models are convex, we are guaranteed global optima. We look at a few scenarios below.

Model 1: Budget $=\$ 9,000$

Solving Model 1 we find that the warehouse is located at $X=204, Y=148$ with drone nests at (46, 207), (228, 197), (282, 55) serving clusters 1,2 and 3 respectively. Hence, for example, a truck will travel from $(204,148)$ to $(46,207)$ where a drone will be loaded to fly to demand cluster 1 . From the computer output, it is noted that drone nest 3 (serving cluster 3) is maximally distanced from the drone nest. Further we examine how budget changes affect the total weighted time. This is given in Figure 2 below. 


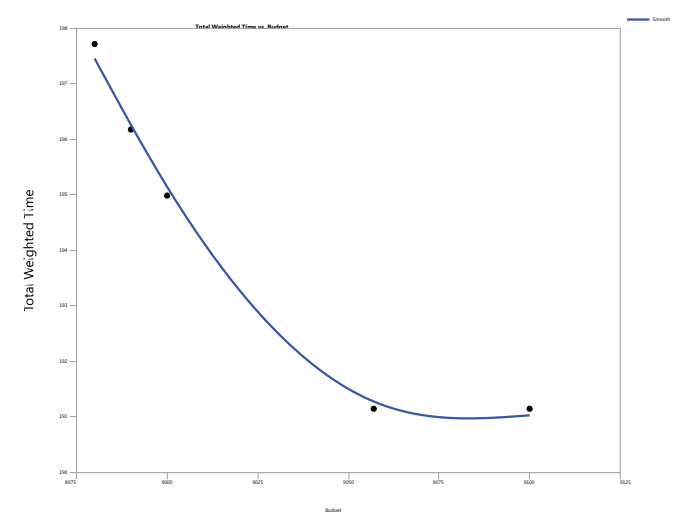

Figure 2. Total weighted time versus budget

Increasing the budget up to about $\$ 9057$ will decrease the total weighted time but further increases do not help since the drone distance constraint becomes active. Hence in this scenario, there is no need for a budget allocation greater than \$9057. At the other extreme any budget allocation less than $\$ 8980$ will not meet service needs.

As drone technology improves, clearly the distance that a drone can fly from its' nest will increase. Below we give a table that that looks at the variation of maximal drone distance on warehouse and drone nest location. In order to get a richer set of results we have increased the budget by $\$ 1000$.

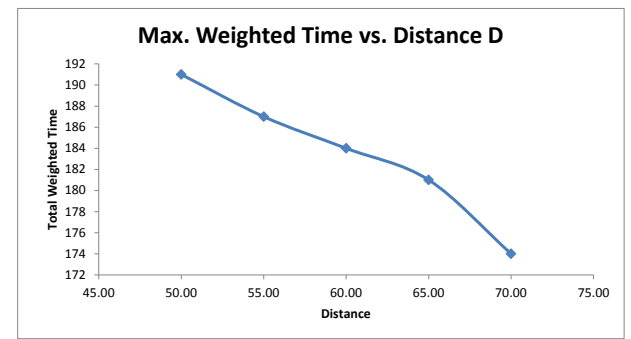

Figure 3. Max weighted time versus distance

We note from Figure 3 that as the range $D$ of a drone increases, the total weighted time decreases since more travel is done by faster drones than trucks.

Table 4. Location versus drone range

\begin{tabular}{|l|l|l|l|l|}
\hline$D$ & $(X, Y)$ & $\left(x_{1}, y_{1}\right)$ & $\left(x_{2}, y_{2}\right)$ & $\left(x_{3}, y_{3}\right)$ \\
\hline 50 & $(200,151)$ & $(48,205)$ & $(267,191)$ & $(283,56)$ \\
\hline 55 & $(200,151)$ & $(52,203)$ & $(262,189)$ & $(279,60)$ \\
\hline 60 & $(199,151)$ & $(57,201)$ & $(258,186)$ & $(275,63)$ \\
\hline 65 & $(198,150)$ & $(62,199)$ & $(253,184)$ & $(271,67)$ \\
\hline 70 & $(198,150)$ & $(66,197)$ & $(149,181)$ & $(266,69)$ \\
\hline
\end{tabular}

From table 4 above, we note that the location of the warehouse changes minimally $(200,151)$ to $(198,150)$. On the other hand the drone nests can change location significantly; in the case of nest " 1 " from $(48,205)$ to $(66,197)$. However since all the requirements for a drone nest can be carried in a container, this should not be of practical significance.

Model 2: Budget $=\$ 9,000$

In this case, we find that the warehouse is located at $X=177, Y=157$ with drone nests at $(44,209)$, (293, 202) and $(287,42)$. Note that the location of the drone nests are not too different from Model 1 which minimizes total weighted time. In this case, the computer output shows us that the worst weighted service time is to demand point 1 in cluster 1 . Below we contrast the results from both models by comparing the total weighted times to service each demand point $j$ from drone nest $i$.

Table 5. Total weighted time comparison

\begin{tabular}{|l|l|l|}
\hline $\begin{array}{l}\text { Drone } \\
\text { Nest/Demand } \\
\text { Point }\end{array}$ & $\begin{array}{l}\text { Total Weighted } \\
\text { Time Model 1 }\end{array}$ & $\begin{array}{l}\text { Total Weighted } \\
\text { Time Model 2 }\end{array}$ \\
\hline 1,1 & 99 & 85 \\
\hline 1,2 & 95 & 81 \\
\hline 1,3 & 95 & 80 \\
\hline 2,1 & 29 & 36 \\
\hline 2,2 & 28 & 36 \\
\hline 2,3 & 29 & 35 \\
\hline 3,1 & 58 & 74 \\
\hline 3,2 & 58 & 74 \\
\hline 3,3 & 55 & 71 \\
\hline
\end{tabular}

We note that cluster 1 served by drone nest 1 gets better service using Model 2 (more equitable model) whereas clusters 2 and 3 get slightly worse service. The worst served demand point (point 1 in cluster 1) has total weighted service time reduced from 99 to 85.

In an undeveloped country, it may be advisable to locate the warehouse at the international airport since this is the point of entry for medical supplies. This involves fixing the location of the warehouse say close to the international airport. Suppose then that the warehouse location is fixed at the origin so that $X=0$ and $Y=0$ is fixed. In this case, we find that the location of the drone nests are at $(21,175),(283,142)$ and $(283,24)$ for Model 1 for Budget $=\$ 12,000$ and at (26, 192), (297, 200), (281, 31) for Model 2 with Budget $\$ 15,000$. The extra budget is necessary due to the longer distance that trucks travel from the airport to reach a drone nest.

\section{Concluding remarks}

Drones, along with mobile technology, are enabling developing countries to leapfrog ahead with healthcare delivery to remote locations even with an 
unreliable road infrastructure. As stated earlier, only a third of Africans live within two kilometers of a road that functions year-round [12]. Even in developed countries, disasters, such as earthquakes and fires, can render roads inaccessible. Furthermore, extreme weather and city congestion can be an obstacle to emergency medical delivery.

Drone technology and its components, such as GPS and lithium batteries, are available and improving at a rapid pace. Despite issues related to privacy, security, safety and regulation, drones can provide beneficial and humanitarian applications, especially related to healthcare. Consequently, drone healthcare delivery to inaccessible locations is likely to become more ubiquitous in the near future.

This paper discusses some innovative applications of drones in healthcare. Our contribution of two models, that use a tandem strategy involving traditional land transportation followed by drone delivery, will facilitate more timely, efficient and economical healthcare delivery. Healthcare costs are a major concern in both developed and developing countries. The models use a budget constraint while providing location decisions for warehouses and drone nests that enable timely delivery. Since time is of the essence in an emergency, faster response would prevent medical trauma and potentially save lives.

Our models could be used by drone companies, delivery companies, healthcare organizations, humanitarian organizations or governments. In some cases, governments could partner with drone companies, such as Rwanda with Zipline.

We are currently extending these models in a number of directions. Here we have used an empirically derived form of a distance metric for truck delivery. A better representation may be to explicitly model the actual road network. Future research can also investigate how many drones are needed at a particular drone nest and how well a network provides coverage for a region. Another issue is to account for the effect of obstacles such as a high mountain on a drone path and integrate it into the location model. For drone delivery in a metropolitan area, paths need to be routed around tall buildings and airports, for example. Drone healthcare delivery is a new field with many opportunities for impactful future research.

\section{Appendix}

Here we give data that was used in the numerical work on the two models.
Table 6. Weights associated with travel from drone nest $\boldsymbol{i}$ to demand point $\boldsymbol{j}$.

\begin{tabular}{|l|l|l|l|}
\hline$w$ & 1 & 2 & 3 \\
\hline 1 & 5 & 3 & 6 \\
\hline 2 & 4 & 2 & 1 \\
\hline 3 & 5 & 4 & 2 \\
\hline
\end{tabular}

For example, $w_{11}=5$ is the weight associated with travel from drone nest 1 to demand point 1 in cluster 1.

Table 7. $x$ Coordinates of demand points

\begin{tabular}{|l|l|l|l|}
\hline$a$ & 1 & 2 & 3 \\
\hline 1 & 0 & 30 & 41.2 \\
\hline 2 & 306 & 300 & 306 \\
\hline 3 & 306 & 330 & 282 \\
\hline
\end{tabular}

Table 8. $y$ Coordinates of demand points

\begin{tabular}{|l|l|l|l|}
\hline$b$ & 1 & 2 & 3 \\
\hline 1 & 220 & 200 & 212 \\
\hline 2 & 200 & 220 & 222 \\
\hline 3 & 12 & 40 & 24 \\
\hline
\end{tabular}

For example, demand point 1 in cluster 1 is at $(0,220)$.

\section{References}

[1] N. Agatz, P. Bouman and M. Schmidt, Optimization Approaches for the Traveling Salesman Problem with Drone, ERIM Report Series Research in Management, Erasmus Research Institute of Management, Erasmus University Rotterdam, 2015.

[2] A. Choi-Fitzpatrick, D. Chavarria, E. Cychosz, J. P. Dingens, M. Duffey, K. Koebel, S. Siriphanh, M. Yurika Tulen, H. Watanabe, T. Juskauskas, J. Holland and L. Almquist, Up in the Air: A Global Estimate of Non-Violent Drone Use 2009-2015, Joan B. Kroc School of Peace Studies at Digital@USanDiego, University of SanDiego, 2016.

[3] R. Clarke, "Understanding the drone epidemic", Computer Law \& Security Review, 30 (2014), pp. 230-246.

[4] DHL, Successful Trial Integration of DHL Parcelcopter into Logistics Chain, 2016.

[5] Z. Drezner and H. Hamacher, eds., Facility Location: Applications and Theory, Springer, 2004.

[6] D. Esler, Drone Revolution, Business \& Commercial Aviation, 2015.

[7] S. M. Ferrandez, T. Harbison, T. Weber, R. Sturges and R. Rich, "Optimization of a Truck-drone in Tandem Delivery Network Using K-means and Genetic Algorithm", 
Journal of Industrial Engineering and Management, 9 (2016), pp. 374-388.

[8] R. Fourer, D. M. Gay and B. W. Kernigham, AMPL: A Modeling Language for Mathematical Programming, Cengage Learning, 2002.

[9] S. French, Drone delivery is already here - and it works, Marketwatch, 2015.

[10] M. Hackman and J. Nicas, Drone Delivers Medicine to Rural Virginia Clinic, Wall Street Journal, 2015.

[11] I. Hong, M. Kuby and A. Murray, Deviation flow refueling location model for continuous space: commercial drone delivery system for urban area, 13th International Conference on GeoComputation, The University of Texas at Dallas, Richardson, Texas, 2015.

[12] O. Khazan, A Drone to Save the World, The Atlantic, 2016.

[13] C. C. Murray and A. G. Chu, "The flying sidekick traveling salesman problem: Optimization of drone-assisted parcel delivery", Transportation Research Part C: Emerging Technologies, 54 (2015), pp. 86-109.

[14] J. Pepitone, First FAA-Approved Drone Delivery Drops Medicine in Virginia, NBC News, 2015.

[15] A. Ponza, "Optimization of Drone-Assisted Parcel Delivery", (2015).

[16] C. Preimesberger, Drones Will Soon Be Dropping Medicines to Save Lives in Rwanda, eWeek, 2016.

[17] M. Prigg, The ambulance drone that could save your life, Daily Mail, 2014.

[18] D. A. Raffaello, "Guest Editorial Can Drones Deliver?", IEEE Transactions on Automation Science and Engineering, 11 (2014).

[19] A. Raptopoulos, No roads? There's a drone for that, TEDGlobal 2013, 2013.

[20] A. Tilley, UPS Experiments With Drone Delivery In Partnership With Zipline, Forbes, 2016.

[21] H. Varnholt, DHL's Drone Demonstration Fails to Deliver, Wall Street Journal, 2016.

[22] J. Villasenor, What Is a Drone, Anyway?, Scientific American, 2012.

[23] X. Wang, S. Poikonen and B. Golden, "The vehicle routing problem with drones: Several worst-case results", Optim Lett (2016), pp. 1-19.
[24] A. Welch, A cost-benefit analysis of Amazon Prime Air, Economics Department, University of Tennessee at Chattanooga, 2015. 